\title{
Analisis Usaha dan Nilai Tambah Pengolahan Dodol Rumput Laut Skala Rumah Tangga di Desa Loon, Kecamatan Kei Kecil, Kabupaten Maluku Tenggara
}

(Business Analysis and Added Value of Processing Dodol Seaweed in Household Scale of Loon Village, Kei Kecil Sub-District, Southeast Maluku District)

\section{Anna Kartika Ngamel}

\author{
Program Studi Agribisnis Perikanan, Politeknik Perikanan Negeri Tual
}

Alamat email : annangamel@yahoo.com

Diterima/disetujui : 27 Mei 2015/ 7 Juni 2015

\begin{abstract}
This study aimed to quantify the value of profit, the value of break-even point, the added value and the ratio of added value to the processing business of dodol seaweed in Loon Village, Kei Kecil Sub-District, Southeast Maluku District. The method used in this study was a survey method with qualitative and quantitative approaches. The location of the research was determined purposively, where the population was the entrepreneur of dodol seaweed in Loon village. The analytical method used was the analysis of profit, break-even and added value Hayami method. The results showed that the business of dodol seaweed deserves to be developed with a profit of $R p$ 26118 million,- per year. The cumulative gain value $(R / C$ ratio) was 1.77 , which means that the processing business of dodol seaweed was feasible because it meets the eligibility criteria value greater than one. The obtained break-even point value was 1.694 dus, (Rp 11 300) and the cost was Rp 26.97 million. The added value created from each kilogram of dried seaweed was Rp 197 792 , with a ratio of $79.12 \%$ of the production value. According to Hubeis (1997), this added value ratio is a high added value category that has a ratio of $>40 \%$.
\end{abstract}

Keyword : analysis of profit, break even, added value, dodol seaweed.

\section{PENDAHULUAN}

Salah satu bentuk pembangunan kelautan dan perikanan yang telah ditetapkan oleh Kementerian Kelautan dan Perikanan adalah pengembangan industri yang mengolah komoditas perikanan primer menjadi produk olahan. Produk olahan tersebut meliputi produk antara (intermediate product) dan produk akhir (finish product) seperti industri pengolahan makanan dan minuman, industri bio-farmaka, industri bio-energi, industri pengolahan hasil ikutan (by product).

Dalam perkembangan ekonomi suatu negara, acapkali sektor pertanian diusahakan menjadi sektor tangguh yang mampu mendukung sektor industri. Dukungan pertanian pada sektor industri antara lain berupa penyediaan bahan baku dari hasil-hasil pertanian. Pembangunan industri hasil-hasil pertanian akan meningkatkan nilai tambah dari hasil-hasil pertanian dan menciptakan kesempatan kerja. Melalui proses pengolahan, produk-produk pertanian akan menjadi lebih beragam kegunaannya (Soekartawi 1993). Menurut Kustiari (2011) nilai tambah dalam proses pengolahan dapat didefinisikan sebagai selisih antara nilai produk dengan biaya bahan baku dan input lainnya, tidak termasuk tenaga kerja, sedangkan marjin adalah selisih antara nilai produk dan harga bahan bakunya saja. Dalam marjin tercakup komponen faktor produksi yang digunakan yaitu tenaga kerja, input lainnya dan balas jasa pengusaha pengolahan. 
Rumput laut cukup mudah dibudidayakan dan merupakan salah satu komoditi potensial yang dapat menjadi andalan bagi upaya pengembangan usaha skala kecil dan menengah. Berdasarkan data Badan Koordinasi Penanaman Modal Daerah diketahui bahwa lahan potensial untuk budidaya rumput laut di Maluku 23.613 Ha. Lahan yang telah dimanfaatkan baru sebesar $8.258 \mathrm{Ha}$. Daerah penghasil rumput laut meliputi Kabupaten Seram Bagian Barat, Maluku Tengah, Maluku Tenggara, Maluku Barat Daya dan Kepulauan Aru. Hal ini menunjukkan bahwa peluang untuk pengembangan budidaya maupun industri rumput laut masih sangat terbuka dan berpotensi untuk dikembangkan.

Usaha pengolahan rumput laut seperti produk olahan dodol rumput laut di Kabupaten Maluku Tenggara telah cukup lama ada baik secara individu maupun kelompok usaha. Namun usaha pengolahan ini belum berkembang secara baik dan kurang mendapat perhatian serius dari Pemda. Hal ini terkait dengan pemberian bantuan kepada kelompok masyarakat yang tidak tepat sasaran dan kurangnya informasi pasar. Masalah ini mengakibatkan masyarakat enggan untuk bertahan lebih lama dalam melakukan usaha tersebut. Pada saat ini usaha dodol rumput laut hanya dibuat ketika ada permintaan atau pesanan dari konsumen.

Desa Loon, Kecamatan Kei Kecil, sebagai salah satu sentra rumput laut di Kabupaten Maluku Tenggara telah memiliki beberapa kelompok usaha olahan rumput laut. Kelompok nelayan "Sibit" merupakan salah satu kelompok yang melakukan usaha olahan dodol rumput laut. Kelompok ini didirikan pada tahun 2010. Namun usaha kelompok nelayan ini juga hanya berjalan jika ada permintaan atau pesanan. Kelompok ini juga pernah memperoleh bantuan peralatan dari Pemerintah Daerah namun bantuan tersebut tidak dapat dimanfaatkan secara optimal karena tidak disertai dengan pengetahuan tentang penggunaan peralatan tersebut. Adanya industri olahan rumput laut tentunya dapat memberikan nilai tambah, baik kepada nelayan pembudidaya maupun kelompok yang melakukan usaha olahan rumput laut. Sehingga pada akhirnya keberadaan usaha olahan rumput laut dapat mendorong pertumbuhan ekonomi Kabupaten Maluku Tenggara. Oleh karena itu penulis tertarik untuk melakukan analisis usaha dan nilai tambah pengolahan dodol rumput laut. Tujuan penelitian ini yaitu melakukan analisis usaha dan analisis nilai tambah pengelolaan rumput laut.

\section{METODOLOGI}

Penelitian dilakukan di Desa Loon, Kecamatan Kei Kecil, Kabupaten Maluku Tenggara. Penelitian dilaksanakan pada bulan Mei - Juli 2014. Penentuan lokasi dilakukan secara purposive karena Desa Loon merupakan desa tempat pembuatan dodol rumput laut di Kabupaten Maluku Tenggara. Penelitian menggunakan metode survei dengan pendekatan secara kualitatif dan kuantitatif melalui wawancara dengan Kelompok Nelayan Sibit yang melakukan usaha pengolahan dodol rumput laut.

Data yang dikumpulkan meliputi data primer dan data sekunder. Data yang dikumpulkan meliputi biaya produksi, jumlah produksi, harga produk, dan proses produksi. 


\section{Analisis Data}

Perhitungan keuntungan diketahui dengan menggunakan analisis Laba / Rugi dengan menggunakan rumus:

Keuntungan $=$ Penerimaan - Total Biaya .

$R / C$ Ratio dihitung dengan menggunakan rumus:

Total Penerimaan

$R / C$ Ratio $=$

Total Biaya

Kriteria sebagai berikut:

- Jika Nilai $R / C$ Ratio $=1$, artinya usaha tidak untung atau rugi

- Jika Nilai $R / C$ Ratio $>1$, artinya usaha menguntungkan / efisien

- Jika Nilai $R / C$ Ratio < 1, artinya usaha merugikan / tidak efisien

Analisis titik impas merupakan suatu cara untuk mengetahui berapa volume atau penjualan minimum produk agar perusahaan tidak mengalami kerugian atau tidak memperoleh keuntungan. Analisis titik impas atau Break Event Point (BEP) menggunakan persamaan sebagai berikut :

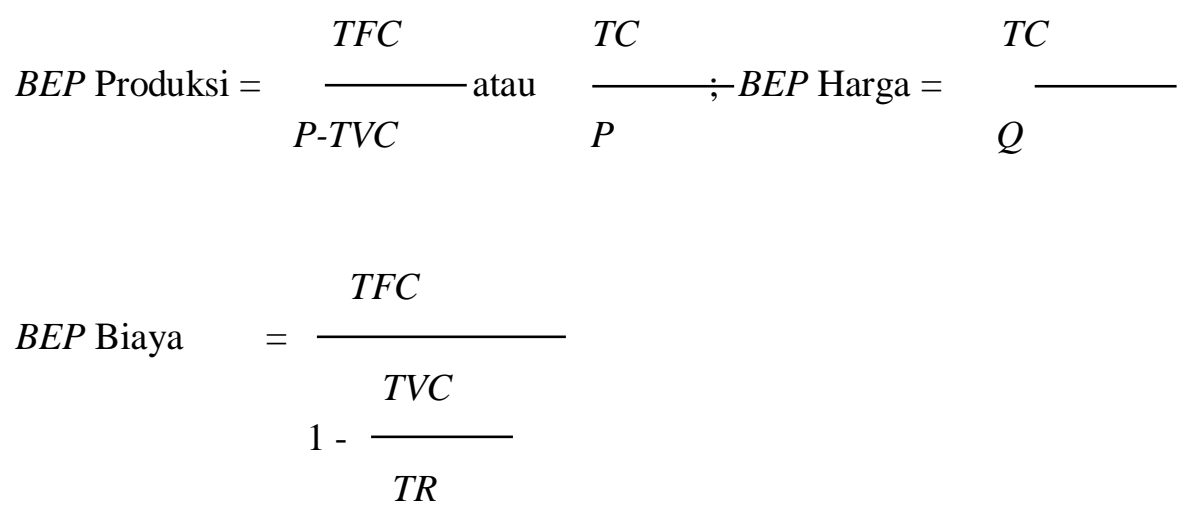

Analisis penghitungan nilai tambah pengolahan dodol rumput laut menggunakan formula yang disajikan pada Tabel 1 (Hayami 1987 dalam Sudiyono 2001).

Ada tiga indikator rasio nilai tambah (Hubeis 1997), yaitu:

1) Jika besarnya rasio nilai tambah $<15 \%$, maka nilai tambahnya rendah;

2) Jika besarnya rasio nilai tambah $15 \%$ - 40\%, maka nilai tambahnya sedang;

3) Jika besarnya rasio nilai tambah $>40 \%$, maka nilai tambahnya tinggi. 
Tabel 1. Format Analisis Nilai Tambah Pengolahan

\begin{tabular}{|c|c|c|}
\hline \multicolumn{2}{|r|}{ Output, Input, Harga } & \multirow{2}{*}{$\frac{\text { Formula }}{\mathrm{A}}$} \\
\hline 1 & Hasil produksi (kg / tahun) & \\
\hline 2 & Bahan baku (kg / tahun) & B \\
\hline 3 & Tenaga kerja (HOK) & $\mathrm{C}$ \\
\hline 4 & Faktor konversi (1 / 2) & $\mathrm{A} / \mathrm{B}=\mathrm{M}$ \\
\hline 5 & Koefisien tenaga kerja (3 / 2) & $\mathrm{C} / \mathrm{B}=\mathrm{N}$ \\
\hline 6 & Harga produk $(\mathrm{Rp} / \mathrm{Kg})$ & $\mathrm{D}$ \\
\hline 7 & Upah rerata $(\mathrm{Rp} / \mathrm{HOK})$ & $\mathrm{E}$ \\
\hline \multicolumn{2}{|r|}{ Pendapatan } & \\
\hline 8 & Harga bahan baku ( Rp / kg) & $\mathrm{F}$ \\
\hline 9 & Sumbangan input lain $(\mathrm{Rp} / \mathrm{kg})$ & G \\
\hline 10 & Nilai produk $(4 \times 6)(\mathrm{Rp} / \mathrm{kg})$ & $M \times D=K$ \\
\hline \multirow[t]{2}{*}{11} & a. Nilai tambah (10-8-9) ( Rp / kg) & $\mathrm{K}-\mathrm{F}-\mathrm{G}=\mathrm{L}$ \\
\hline & b. Rasio nilai tambah (11.a / 10) (\%) & $(\mathrm{L} / \mathrm{K}) \%=\mathrm{H} \%$ \\
\hline \multirow[t]{2}{*}{12} & a. Imbalan tenaga kerja $(5 \times 7)(\mathrm{Rp} / \mathrm{kg})$ & $\mathrm{N} \times \mathrm{E}=\mathrm{P}$ \\
\hline & b. Bagian tenaga kerja (12.a. / 11.a.) (\%) & $(\mathrm{P} / \mathrm{L}) \%=\mathrm{Q} \%$ \\
\hline \multirow[t]{3}{*}{13} & a. Keuntungan $(10-11 . a)$ & $\mathrm{K}-\mathrm{L}=\mathrm{R}$ \\
\hline & b. Tingkat keuntungan (13.a / 10) (\%) & $(\mathrm{R} / \mathrm{K}) \%=0 \%$ \\
\hline & Balas Jasa Untuk Faktor Produksi & \\
\hline \multirow[t]{4}{*}{14} & Margin $(\mathrm{Rp} / \mathrm{kg})$ & $\mathrm{K}-\mathrm{F}=\mathrm{S}$ \\
\hline & - Pendapatan tenaga kerja langsung $12 \mathrm{a} /(14 \mathrm{x} 100)$ & $\mathrm{P} /(\mathrm{S} X 100)=\mathrm{T}$ \\
\hline & - Sumbangan input lain 9 / (14 x 100) & $\mathrm{G} /(\mathrm{S} X 100)=\mathrm{U}$ \\
\hline & - Keuntungan perusahaan 13a / (14 x 100) & $\mathrm{R} /(\mathrm{S} X 100)=\mathrm{V}$ \\
\hline
\end{tabular}

Sumber: Hayami dalam Sudiyono, 2001

\section{HASIL DAN PEMBAHASAN}

\section{Keragaan Produk Olahan Dodol Rumput Laut}

Dodol rumput laut yang dihasilkan oleh kelompok nelayan "Sibit" Desa Loon Kecamatan Kei Kecil merupakan salah satu bentuk penganan khas Maluku Tenggara. Penganan ini biasanya dibuat ketika ada pesanan yang berasal dari daerah Maluku Tenggara dan Kota Tual atau dari luar daerah seperti Fak-Fak dan Kaimana. Harga jual produk per dus Rp 20 000,-. Selain diproduksi ketika ada pesanan, produk olahan ini juga diproduksi setiap minggu. Dalam sebulan melakukan proses produksi sebanyak 4 (empat) kali yang menghasilkan 250 dus dodol rumput laut. 
Tabel 2. Struktur Biaya Produksi Olahan Dodol Rumput Laut

\begin{tabular}{|c|c|c|c|c|c|}
\hline No & Struktur Biaya & $\begin{array}{l}\text { Volume } \\
\text { / Satuan }\end{array}$ & $\begin{array}{c}\text { Biaya per } \\
\text { Satuan } \\
(\mathrm{Rp})\end{array}$ & $\begin{array}{c}\text { Jumlah Biaya } \\
\text { per Periode } \\
\text { (Rp) }\end{array}$ & $\begin{array}{c}\text { Jumlah Biaya } \\
\text { Satu Tahun }\end{array}$ \\
\hline \multirow[t]{2}{*}{1} & Bahan Baku: & & & & \\
\hline & Rumput Laut & $5 \mathrm{Kg}$ & $10000,-$ & $50000,-$ & $2400000,-$ \\
\hline \multirow[t]{4}{*}{2} & $\begin{array}{l}\text { Bahan Campuran: } \\
\text { a. Gula Pasir dan } \\
\text { Gula Aren }\end{array}$ & $2 \mathrm{Kg}$ & 15 000,- & 30 000,- & $1440000,-$ \\
\hline & $\begin{array}{l}\text { b. Tepung Ketan } \\
\text { Putih dan } \\
\text { Tepung Beras }\end{array}$ & $2 \mathrm{Kg}$ & $12000,-$ & $24000,-$ & $1152000,-$ \\
\hline & $\begin{array}{l}\text { c. Kelapa Parut } \\
\text { d. Garam secukupnya dan }\end{array}$ & 3 Buah & $2500,-$ & $7500,-$ & $360000,-$ \\
\hline & $\begin{array}{l}\text { aroma perasa } \\
\text { e. Minyak Tanah }\end{array}$ & 5 Liter & $\begin{array}{l}10000,- \\
4500,-\end{array}$ & $\begin{array}{l}10000,- \\
22500,-\end{array}$ & $\begin{array}{l}480000,- \\
1080000,-\end{array}$ \\
\hline 3 & Tenaga Kerja & 2 Orang & $200000,-$ & $400000,-$ & 4800 000,- \\
\hline 4 & Sewa Listrik & 6 Bulan & $100000,-$ & $600000,-$ & 7200 000,- \\
\hline 5 & Izin Usaha & $\begin{array}{c}1 \\
\text { Periode }\end{array}$ & $50000,-$ & $50000,-$ & $50000,-$ \\
\hline 6 & Biaya Pemasaran & 6 Bulan & & $400000,-$ & $800000,-$ \\
\hline 7 & Biaya Perawatan & 6 Bulan & & $500000,-$ & 1000 000,- \\
\hline 8 & Biaya Penyusutan & & & & $13120000,-$ \\
\hline
\end{tabular}

Sumber: Data Primer Diolah, 2014

\section{Struktur Biaya dan Proses Pembuatan Dodol Rumput Laut}

Bahan baku yang dibutuhkan untuk proses pembuatan dodol rumput laut yaitu rumput laut kering sebanyak $5 \mathrm{~kg}$ per kali produksi. Bahan pelengkap lainnya terdiri atas gula pasir dan gula aren masing-masing sebanyak $2 \mathrm{~kg}$, tepung ketan putih dan tepung beras masing-masing sebanyak $2 \mathrm{~kg}$, kelapa parut 3 buah, garam dan aroma perasa secukupnya. Kebutuhan bahan baku dapat dilihat pada Tabel 2 .

Produksi dodol rumput laut dalam satu tahun dilakukan sebanyak 48 kali. Besarnya total biaya produksi dalam satu tahun Rp 26970 000,-. Rincian kebutuhan biaya produksi per periode dan per tahun disajikan pada Tabel 2.

Usaha pengolahan dodol rumput laut membutuhkan investasi peralatan seperti meja, blender, timbangan, kompor, oven dan lain-lain. Total biaya investasi Selain biaya produksi, usaha olahan dodol rumput laut mencapai Rp 49,92 juta. Rincian peralatan dan biaya investasi dapat dilihat pada Tabel 3 . 
Tabel 3. Rincian Biaya Investasi Usaha Olahan Dodol Rumput Laut

\begin{tabular}{|c|c|c|c|c|c|c|c|}
\hline No & Komponen Biaya & Sat & Vol & $\begin{array}{l}\text { Harga per } \\
\text { Satuan (Rp) }\end{array}$ & $\begin{array}{c}\text { Jumlah } \\
\text { Biaya (Rp) }\end{array}$ & $\begin{array}{l}\text { Umur } \\
\text { Ekonomi } \\
\mathrm{s} \text { (Tahun) }\end{array}$ & $\begin{array}{c}\text { Nilai } \\
\text { Penyusutan } \\
\text { (Rp) }\end{array}$ \\
\hline 1 & Meja Preparasi & Unit & 1 & $4600000,-$ & $4600000,-$ & 5 & $920000,-$ \\
\hline 2 & Blender & Unit & 3 & $800000,-$ & $2400000,-$ & 5 & $480000,-$ \\
\hline 3 & Wadah Perendam & Buah & 4 & $200000,-$ & $800000,-$ & 2 & $400000,-$ \\
\hline 4 & Keranjang/Trays & Buah & 4 & $200000,-$ & $800000,-$ & 2 & $400000,-$ \\
\hline 5 & $\begin{array}{l}\text { Timbangan } \\
\text { Bumbu } 20 \mathrm{Kg}\end{array}$ & Buah & 2 & $200000,-$ & $400000,-$ & 3 & $133000,-$ \\
\hline 6 & $\begin{array}{l}\text { Kompor Hock } 32 \\
\text { Sumbu }\end{array}$ & Buah & 3 & $800000,-$ & $2400000,-$ & 3 & $800000,-$ \\
\hline 7 & Pisau Stainless & Buah & 1 & $160000,-$ & $160000,-$ & 3 & 53 333,- \\
\hline 8 & Wajan & Buah & 4 & $900000,-$ & $3600000,-$ & 3 & $1200000,-$ \\
\hline 9 & Cetakan Dodol & Buah & 4 & 75 000,- & 300 000,- & 3 & $100000,-$ \\
\hline 10 & Bahan Kemasan & Buah & 800 & $3000,-$ & $2400000,-$ & 3 & $800000,-$ \\
\hline 11 & Penutup Plastik & Buah & 1 & $8500000,-$ & $8500000,-$ & 3 & $2833333,-$ \\
\hline 12 & $\begin{array}{l}\text { Oven Pengering } \\
\text { Bertingkat }\end{array}$ & Unit & 2 & $10700000,-$ & $21400000,-$ & 5 & $4280000,-$ \\
\hline 13 & $\begin{array}{l}\text { Pencetak } \\
\text { Kadaluarsa }\end{array}$ & Buah & 1 & $2160000,-$ & $2160000,-$ & 3 & $720000,-$ \\
\hline \multicolumn{5}{|c|}{ Jumlah } & $49920000,-$ & & 13120000 ,- \\
\hline
\end{tabular}

Sumber: Data Primer Diolah, 2014

Usaha pengolahan dodol rumput laut yang dilakukan oleh kelompok nelayan "Sibit" ini masih dalam skala rumah tangga. Proses olahan yang dilakukan juga masih sederhana / tradisional. Pertama rumput laut kering direndam selama dua hari dua malam dengan air perasan jeruk nipis yang bertujuan untuk menghilangkan bau amis. Setelah itu, rumput laut dipotong-potong dan diblender jadi bubur, kemudian dimasukkan dalam wajan panas yang berisi santan sambil diaduk sampai mendidih. Bahan penolong berupa gula pasir, gula aren, tepung ketan putih, tepung beras, aroma perasa sesuai selera dan pengawet makanan dimasukkan juga dalam campuran bubur rumput laut yang berisi santan tadi. Adonan tersebut diaduk kurang lebih 2-4 jam hingga adonan masak sesuai kekentalan dodol yang diinginkan, maka adonan tersebut siap untuk dicetak. Proses pembuatan dodol rumput laut dapat ditampilkan pada Gambar 1. 


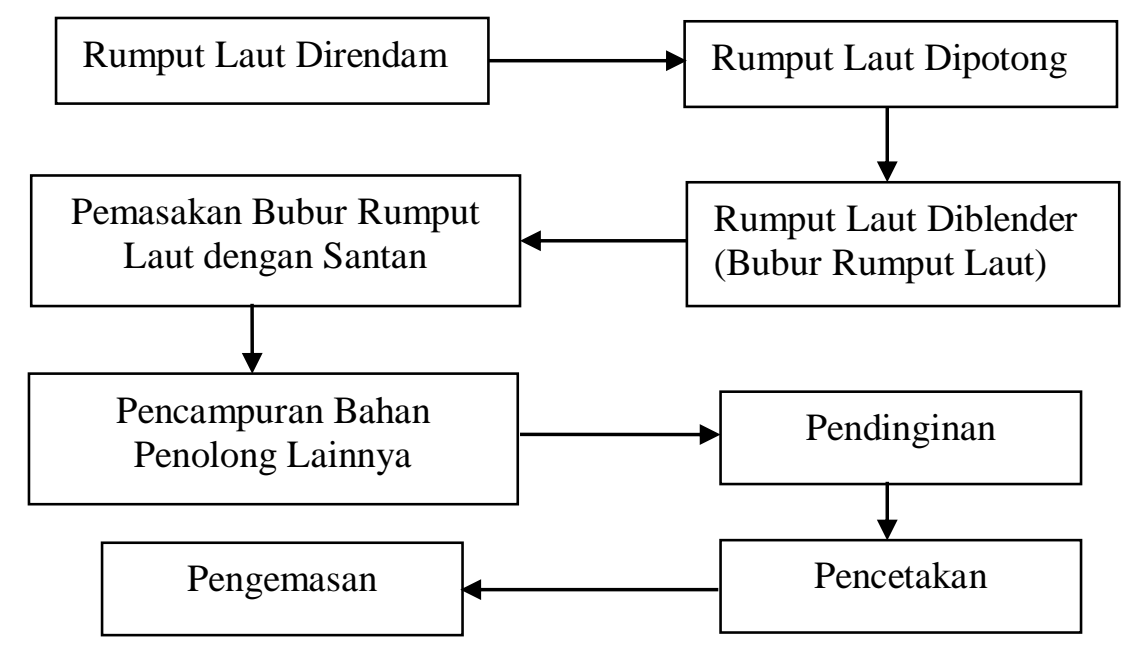

Gambar 1. Proses Pembuatan Dodol Rumput

Proses pembuatan dodol rumput laut dikerjakan oleh 2 orang tenaga kerja. Sekali melakukan proses produksi curahan waktu yang dibutuhkan sekitar 7 (tujuh) jam.

\section{Analisis Usaha}

Menurut Effendi dan Oktariza (2006) analisis usaha merupakan suatu cara untuk mengetahui tingkat kelayakan dari suatu jenis usaha perikanan. Tujuan analisis usaha adalah untuk mengetahui tingkat keuntungan, pengembalian investasi, maupun titik impas suatu usaha. Berbagai antisipasi untuk memperbaiki dan meningkatkan keuntungan perusahaan juga dapat dilakukan apabila dilakukan analisis usaha. Analisis usaha pada usaha perikanan sangat diperlukan mengingat ketidakpastian usaha yang cukup besar, apalagi usaha perikanan tangkap dan pengolahan hasil perikanan yang sangat dipengaruhi oleh musim penangkapan.

Analisis usaha perikanan dapat dilakukan dengan menggunakan beberapa metode analisis usaha sederhana yang mudah diaplikasikan pada usaha perikanan skala kecil dan menengah. Analisis usaha yang dimaksud dalam penelitian ini yaitu analisis Laba / Rugi, Revenue Cost Ratio $(R / C)$ dan Break Event Point $(B E P)$. Berdasarkan penelitian yang telah dilakukan, maka besarnya nilai keuntungan yang diperoleh dalam waktu satu tahun sebesar Rp 26118 000,- yang diperoleh dari total penerimaan sebesar Rp 60000 000,dikurangi biaya total sebesar Rp 33882 000,- . Volume produksi dodol rumput laut dalam satu tahun sebanyak 3000 dus kemasan dikalikan harga jual sebesar Rp 20 000,- per dus.

Besarnya nilai $R C$ Ratio yang diperoleh 1.77 artinya bahwa usaha olahan dodol rumput laut yang dilakukan layak untuk dilaksanakan karena nilainya lebih besar dari 1 . Interpretasi nilai $R C$ Ratio yaitu bahwa dari setiap biaya produksi yang dikeluarkan sebesar Rp 1 000,- maka akan diperoleh penerimaan sebesar Rp 1 770,-.

Besarnya nilai BEP Produksi yang diperoleh 1694 dus kemasan menunjukkan bahwa titik impas atau kondisi perusahaan tidak memperoleh keuntungan dan tidak mengalami kerugian akan dicapai pada saat produksi usaha mencapai 1694 dus kemasan 
dodol rumput laut. Nilai BEP harga sebesar Rp 11 294,- yang dibulatkan menjadi Rp 11 300,- menunjukkan bahwa titik impas perusahaan akan dicapai pada saat harga jual dodol rumput laut Rp 11 300,- per dus. BEP biaya diperoleh sebesar Rp 26970 000,menunjukkan bahwa titik impas akan dicapai pada saat biaya yang dikeluarkan sebesar Rp 26970 000,-.

\section{Analisis Nilai Tambah}

Analisis nilai tambah dilakukan untuk memperoleh informasi mengenai perkiraan nilai tambah, imbalan tenaga kerja, imbalan bagi modal dan manajemen dari setiap kilogram rumput laut yang diolah menjadi dodol rumput laut. Informasi tentang imbalan bagi faktor-faktor produksi dalam proses produksi ini sangat penting bagi pelaku-pelaku bisnis.

Proses produksi dodol rumput laut memerlukan input berupa rumput laut basah dan tenaga kerja sebanyak 2 (dua) orang yang melakukan kegiatan produksi. Peralatan diperlukan untuk mentransformasikan input menjadi output. Bahan penolong yang digunakan dalam proses produksi pengolahan meliputi minyak tanah, listrik dan biaya operasional lainnya. Kapasitas yang digunakan per hari dalam satu kali proses produksi yaitu $5 \mathrm{~kg}$ rumput laut kering dengan tingkat rendemen $12.50 \%$ sehingga menghasilkan 63 dus dodol rumput laut. Struktur biaya produksi dan penerimaan usaha dodol rumput laut di Desa Loon, Kecamatan Kei Kecil, Kabupaten Maluku Tenggara dapat dilihat pada Tabel 4.

Berdasarkan Tabel 4 terlihat bahwa dengan menggunakan bahan baku berupa rumput laut kering sebanyak $240 \mathrm{~kg} /$ tahun dapat menghasilkan dodol rumput laut sebanyak 3000 dus. Usaha ini mampu menyerap tenaga kerja sebanyak $600 \mathrm{HOK} /$ tahun. Dengan demikian, curahan tenaga kerja yang dibutuhkan untuk mengolah $1 \mathrm{~kg}$ rumput laut menjadi dodol rumput laut sebanyak $2.50 \mathrm{HOK} /$ tahun. Apabila harga output sebesar Rp 20 000,-/dus dan faktor konversi sebesar 12.50 maka nilai produksi sebesar Rp 250 000,-. Nilai Produksi ini dialokasikan untuk bahan baku yang berupa rumput laut kering seharga Rp 10 000,- dan sumbangan input-input lainnya seharga Rp 42 208,-Dengan demikian nilai tambah yang tercipta dari setiap kilogram rumput laut kering adalah Rp 197 792,- atau 79.12\% dari nilai produksi. Menurut Hubeis (1997) nilai tambah sebesar $79.12 \%$ merupakan nilai tambah tinggi karena memiliki rasio di atas. 
Tabel 4. Struktur Biaya Produksi dan Penerimaan Usaha Pengolahan Dodol Rumput Laut di Desa Loon, Kabupaten Maluku Tenggara, Tahun 2014

\begin{tabular}{clc}
\hline & \multicolumn{1}{c}{ Output, Input, Harga } & Nilai \\
\hline 1 & Hasil produksi (dus / tahun) & 3000 \\
2 & Bahan baku (kg / tahun) & 240.00 \\
3 & Tenaga kerja (HOK) & 600.00 \\
4 & Faktor konversi & 12.50 \\
5 & Koefisien tenaga kerja & 2.50 \\
6 & Harga produk (Rp / Dus) & 20000.00 \\
7 & Upah rerata (Rp / HOK) & 8000.00 \\
\hline \multicolumn{1}{c}{ Pendapatan } & 10000.00 \\
\hline 8 & Harga bahan baku (Rp / kg) & 42208.33 \\
9 & Sumbangan input lain (Rp / kg) & 250000.00 \\
10 & Nilai produk (Rp / kg) & 197791.67 \\
11 & a. Nilai tambah (Rp / kg) & 79.12 \\
& b. Rasio nilai tambah (\%) & 20000.00 \\
12 & a. Imbalan tenaga kerja (Rp / kg) & 0.10 \\
& b. Bagian tenaga kerja (\%) & 177791.67 \\
13 & a. Keuntungan (Rp/Kg) & 89.89 \\
\hline & b. Rate keuntungan (\%) & 240000.00 \\
\hline & $\quad$ Balas Jasa Untuk Faktor Produksi & 0.00083 \\
\hline 14 & Margin (Rp / kg) & 0.00176 \\
& $\bullet$ Pendapatan tenaga kerja langsung & 0.00741 \\
\hline & • Sumbangan input lain &
\end{tabular}

Sumber: Data Primer Diolah, 2014

Imbalan tenaga kerja dari setiap kilogram rumput laut kering yang diolah menjadi dodol rumput laut sebesar Rp 20 000,-. Dengan demikian pangsa atau bagian tenaga kerja dalam pengolahan rumput laut kering menjadi dodol rumput laut ini sebesar $10 \%$. Analisis lebih lanjut menunjukkan bahwa rate keuntungan sebesar $89.89 \%$ dari nilai produksi, artinya bahwa setiap investasi yang ditanam pada pengolahan dodol rumput laut sebesar Rp 100,- dari nilai produksi yang dihasilkan, maka akan diperoleh keuntungan sebesar Rp 89.89,-. Rate keuntungan yang besar ini harus tetap dipertahankan.

\section{SIMPULAN}

1. Hasil perhitungan analisis keuntungan usaha olahan dodol rumput laut di wilayah penelitian sebesar Rp 26118 000,- per tahun dan memiliki nilai RC Ratio sebesar 1.77 artinya bahwa usaha olahan dodol rumput laut yang dilakukan layak untuk dilaksanakan karena nilainya lebih besar dari 1 .

2. Besarnya nilai titik impas atau BEP Produksi 1694 dus yang menunjukkan bahwa titik impas atau kondisi perusahaan tidak memperoleh keuntungan dan tidak 
mengalami kerugian akan dicapai pada saat produksi usaha mencapai 1.694 dus dodol rumput laut. Nilai BEP harga sebesar Rp 11 300,- per dus menunjukkan bahwa titik impas perusahaan akan dicapai pada saat harga jual dodol rumput laut $\mathrm{Rp} 11$ 300,- per dus. BEP biaya diperoleh sebesar Rp 26970 000,- menunjukkan bahwa titik impas akan dicapai pada saat biaya yang dikeluarkan sebesar Rp 26970 000,-.

3. Usaha olahan dodol rumput laut di wilayah penelitian memiliki nilai tambah sebesar Rp 197 792,- per kg rumput laut kering dan nilai rasio 79.12\% dari nilai produksi. Rasio nilai tambah tersebut merupakan kategori nilai tambah tinggi karena nilainya lebih dari $40 \%$.

\section{DAFTAR PUSTAKA}

Dinas Kelautan dan Perikanan. 2010. Data Survei Lapangan. Kabupaten Maluku Tenggara.

Effendi I dan Oktariza W. 2006. Manajemen Agribisnis Perikanan. Penebar Swadaya. Jakarta.

Hubeis M. 1997. Menuju Industri Kecil Profesional di Era Globalisasi melalui Pemberdayaan Manajemen Industri. Orasi Ilmiah Guru Besar Tetap Ilmu Manajemen Industri. Fakultas Teknologi Pertanian. Institut Pertanian Bogor . Bogor.

Reni Kustiari. 2011. Analisis Nilai Tambah dan Balas Jasa Faktor Produksi Pengolahan Hasil Pertanian. Makalah Disampaikan dalam Seminar Nasional Petani dan Pembangunan Pertanian di Bogor, 12 Oktober 2011.

Sevilla, C.G, dkk. 1993. Pengantar Metode Penelitian. Penerjemah Alimudin Tuwu. Pendamping Alam Syah. Penerbit Universitas Indonesia. Jakarta.

Soekartawi. 1993. Agribisnis Teori dan Aplikasi. PT. Raja Grafindo Persada. Jakarta.

Sudiyono, A. 2001. Pemasaran Pertanian. Universitas Muhammadiyah. Malang

Sugiarto, dkk. 2005. Ekonomi Mikro. Sebuah Kajian Komprehensif. Penerbit PT.

Gramedia Pustaka Utama. Jakarta. 